\title{
An Improved Control Strategy of Four-wire Shunt Active Filter
}

\author{
Yi-hong HE Li-jun SHI \\ Information Engineering College of Wu Yi University \\ Jiangmen, China \\ E-mail: hyh@mail.wyu.cn \\ E-mail: shilijun.1987@163.com
}

\begin{abstract}
When the wind energy is separated from the power grid, explore to find a way by using four-leg active power filter to guarantee power quality to solve the problem caused by four-wire nonlinear load. Considering the disadvantage of phase locked loop, a real-time algorithm of detecting harmonic current based on improved $i_{\mathrm{p}}-i_{\mathrm{q}}$ theory is proposed. The first step is to remove the zero sequence of the three phase current from the original current. And then in order to gain the compensation instructions of the harmonic current and zero sequence current and reactive current, using mean method of slide time window to get rid of the fundamental active current. And based on these steps, a dynamic and real-time simulation model is set up, under the environment of MATLABSIMULINK and the components of the libraries of SimPowSystems. Besides, the model of FCn is used to program. The simulation results show that the detective algorithm of the harmonic current of nonlinear load is correct.
\end{abstract}

Keywords-four-leg active power filter; power quality; slide time window

\section{INTRODUCTION}

Recently, as a kind of new, green and environmental energy, wind energy has been received more and more attention[1-2]. It is becoming a trend to use both conditional power and wind energy. However, the harmonic content in the grid will change in the course of withdrawing wind generators from the conditional power network. It turns out to be a good method to use active power filter (abbrev. APF) to suppress the harmonic so as to guarantee the power quality.

In China, the low-voltage power system is a system of three-phase and four-wire. And there are lots of researches have done about four-leg APF, such as [3] to [8] . Some of them propose to detect the harmonic and reactive current in the power system by means of FBD algorithm. [9] adopts a different way to settle the problem to gain the component of harmonic and reactive current, which is based on $i_{\mathrm{p}}-i_{\mathrm{q}}$ algorithm. Considering both the algorithms used in [7] and [9] need the phase locked loop (abbrev. PLL) and due to the loss of lock, the PLL might cause the problem of difference of phases. Based on this, a new algorithm of real-time detecting harmonic current based on improved $i_{\mathrm{p}}-i_{\mathrm{q}}$ theory is proposed. In order to avoid the PLL and the conditional low pass filter (abbrev. LPF), which is used during the course of obtaining the compensation instructions of the harmonic current, the mean method of slide time window programmed in MATLAB Function model is used. The simulation results show that the detective algorithm proposed is right.

\section{FOUR-LEG APF THEORY}

In the paper, only the moment that wind generators are gotten off from the power system is considered. Fig.1 shows the whole system schematic of four-leg APF. Both the power grid and wind generators provide the energy to the load and four-leg APF aims to guarantee the power quality of load. Besides, wind generators in Fig. 1 is made up of fan blade, gear box and converters.

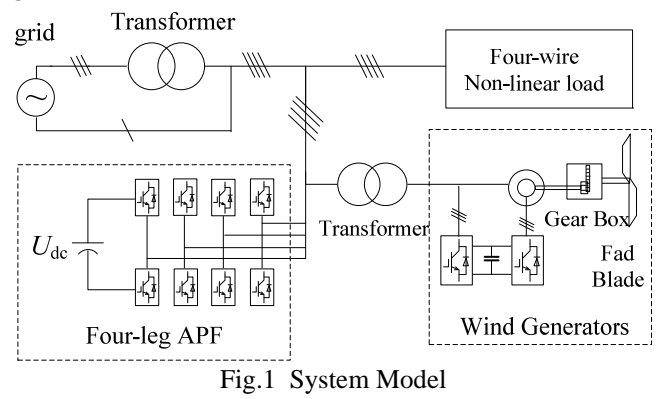

A. Harmonic Detecting Theory

Normally, instantaneous reactive power theory can not be directly used in four-wire situation. Based on the idea of [9], firstly removing zero-sequence current from the detective current of load. Then based on the instantaneous reactive power theory, transform the instantaneous variate to $\alpha-\beta$ coordinate system and multiply with the constant array $\mathrm{C}$ so as to get the three-phase instantaneous active current $i_{\mathrm{p}}$ and reactive current $i_{\mathrm{q}}$.

And then use the method of slide time window to achieve the fundamental current component of load. The value gotten by reference voltage minus the feedback value of DC side is adjusted by Proportion Integration (abbrev. PI) and then added to the DC current branch of active power. By transforming the values back to three-phase coordinate system to get the fundamental current component of load.

Finally, the original current of load subtracts the fundamental current component, remaining the harmonic current component, later which would be used as the compensation instructions. The whole process is shown in Fig.2. 


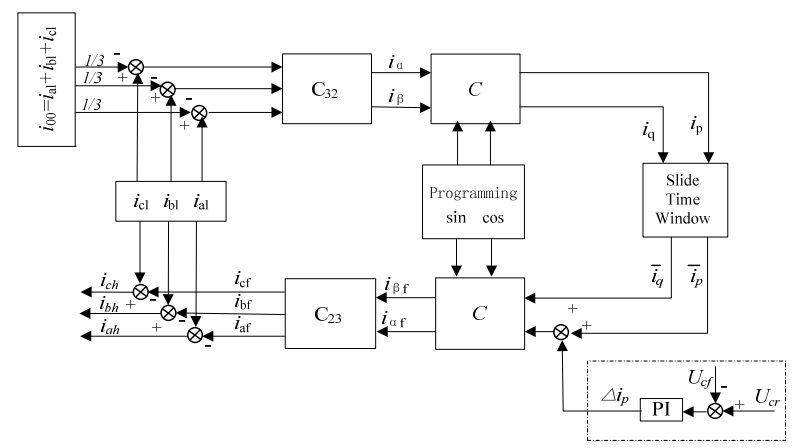

Fig.2 Detection Progress

\section{B. Programming Flowchart}

First of all, a few variate must be defined. In order to use instantaneous reactive theory, it is necessary to pretreat certain variate named $i_{\mathrm{a}}, i_{\mathrm{b}}$ and $i_{\mathrm{c}}$. And the constant array $\mathrm{C}$ is programmed related with the global variate $\mathrm{k}$. In order to simplify the question, we transform the variate to $\alpha-\beta$ coordinate system, then the slide time window comes. If the variate $\mathrm{m}$, which means current loop times, is smaller than the variate $\mathrm{N} 1$, which is the number of sampling points related with the length of the constant array $\mathrm{C}$, the slide time window stores the new data and averages directly the data of active power current $i_{\mathrm{p}}$ and reactive power current $i_{\mathrm{q}}$ to get the fundamental component of load current. If not, the slide time window updates the array members of ip and iq respectively by popping out the original last data and moving the rest back up a place and storing new data into the first place of the array. After adding the component of the voltage of DC side to the active power current, transform all of them back to the normal coordinate system.At last, remove the fundamental component of load current from the original current of load, remaining the harmonic current component. As we can see, Fig.3 shows the whole process.

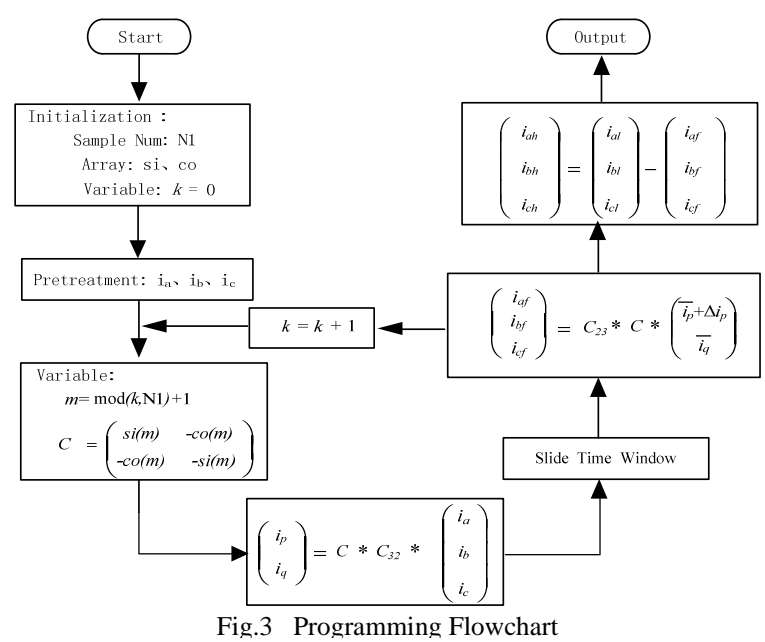

III. SIMULATION MODEL

As shown in Fig.4, the grid voltage goes through a stepdown transformer and the voltage changes from $120 \mathrm{kV}$ down to $25 \mathrm{kV}$. After passing 30 kilometres and another step-down transformer, the voltage turns down to $380 \mathrm{~V}$ and it provides energy to loads. Quite similarly, the wind generators goes by a step-down transformer voltage down to $380 \mathrm{~V}$ and provide energy to loads. Taking the power of loads into account, the wind generators rated power is set $1.5 \mathrm{MW}$ and voltage $575 \mathrm{~V}$.

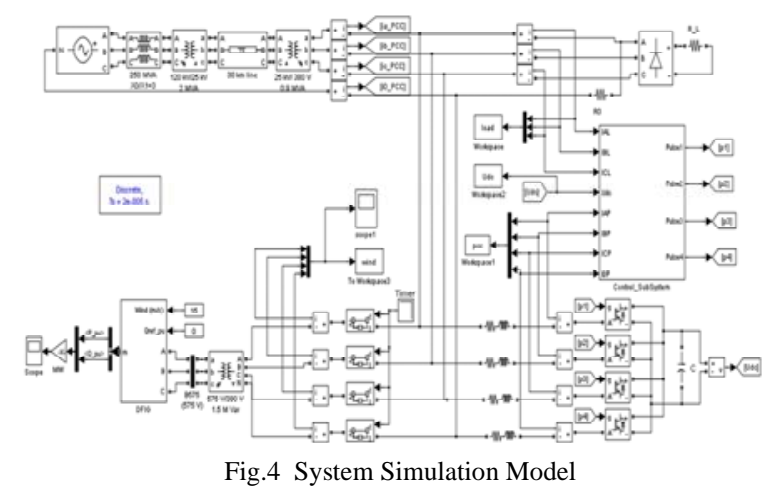

The details of the controlling sub-module is shown in Fig.5. After the model of zero-holding, the original signals access to the function model and the output signals of harmonic current go to the timing comparison circuit so as to drive the circuit of IGBT.

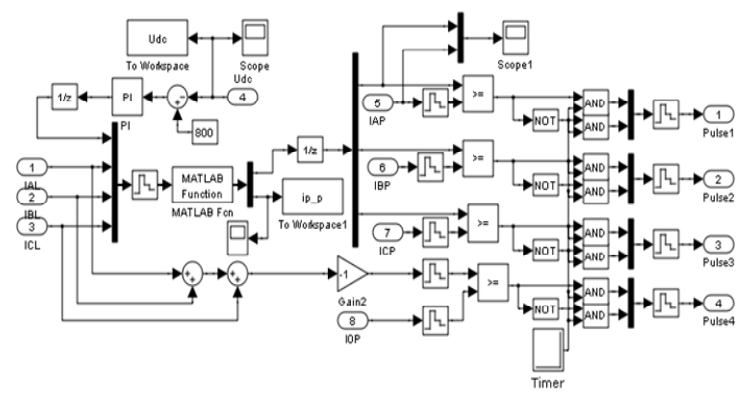

Fig.5 Details of Sub-module

\section{ANALYSIS OF THE SimULATION RESULtS}

Considering that the system model needs to reach a stable state, the start-time of simulation is set at 0.40 second. At the moment of 0.45 second, four-leg APF is added in to the system and when the time comes to 0.50 second, wind generators are removed from the whole system. Fig. 6 shows the current of source.

While four-leg APF is added to the system at 0.45 second, the harmonic burr reduces a lot. And at the moment of 0.50 second, wind generators are withdrawn, the current of source becomes much smaller with much less content of harmonic burr, which tells that the four-leg active power filter does work and performs well in the course of withdrawing the wind turbine generators from the power system.

The reason why the current becomes smaller after wind turbine generators getting off is that wind energy offers energy to loads and the conditional power system at first and when it is cut off, the conditional power system supplies the energy needed by the load. 


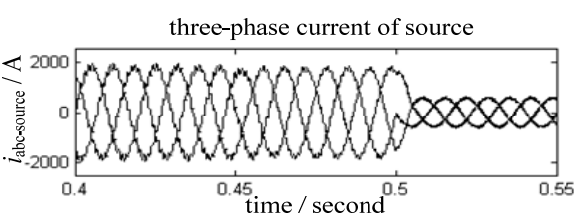

(a)

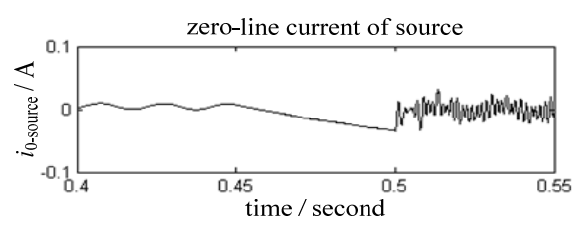

(b)

Fig.6 Four-wire Current of Source

The current of wind energy after transforming displays as Fig.7. As is shown, the harmonic burr turns to be less when four-leg APF is put in the system and turns to be zero when it is cut off. In Fig.7 (b) , we can get a conclusion that fourleg APF has a good affection on the zero-line current of wind generators.

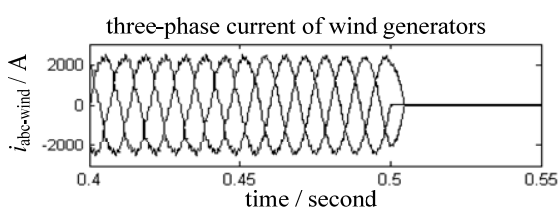

(a)

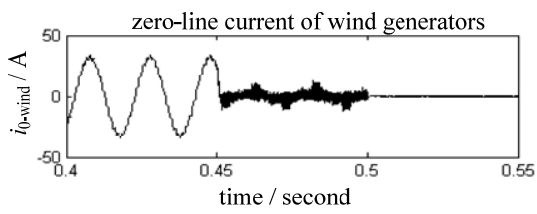

(b)

Fig.7 Four-wire Current of Wind Generators

In order to test the algorithm proposed in this paper, Fig.8 tells the effect of slide time window.

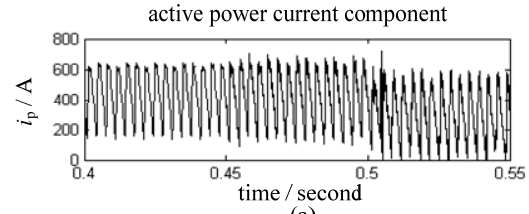

(a)

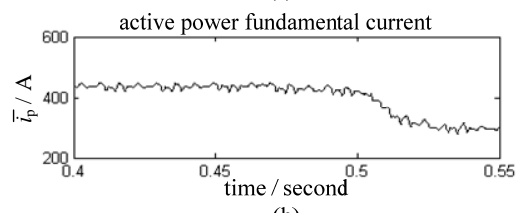

(b)

Fig.8 Test of Slide Time Window
Fig.8.(a) shows the active power current component $i_{\mathrm{p}}$ and Fig.8.(b) tells the output of $i_{\mathrm{p}}$. The signal of active power current component $i_{\mathrm{p}}$ steps down at 0.50 second but keeps relative stable at any other time, which means the slide time window does get good results. Due to the energy provider changing from wind generators to conditional power energy at 0.50 second, both of them turns down at that time.

\section{CONCLUSION}

In order to guarantee the power quality of source during the course of withdrawing the wind generators from the power grid, a real-time algorithm of detecting harmonic current based on improved $i_{\mathrm{p}}-i_{\mathrm{q}}$ theory is proposed and a dynamic and real-time simulation model is set up, under the environment of MATLAB-SIMULINK and the components of the libraries of SimPowSystems. The simulation results show that the detective algorithm of the harmonic current is correct.

\section{REFERENCES}

[1] Sainz L, Mesas J. Deterministic and stochastic study of wind farm harmonic currents[J]. IEEE Transactions on Energy Conversion, vol. 25. 2010, pp.1071-1080

[2] YAO Jun, XIA Xianfeng, CHEN Xiyin, LIAO Yong, "Harmonic Currents Suppression for Full Size Power Grid-connection Converter Used for Wind Power Generation", Proceedings of the CSEE, vol. 32. 2012, pp.17-25,

[3] Aredes M, Hafner I, Heumann K. Three-phase four-wire shunt active filter control stra tegies[J]. $12^{\text {th }}$, vol. 12. IEEE Trans Power Electron, 1997, pp. 311-318.

[4] Peng F Z, Ott G W, Adams D J. Harmonic and reactive power compensation based on the generalized instantaneous reactive power theory for three-phase four-wire systems[J]. IEEE Trans Power Electron,1998, 13(5): 1174-1181.

[5] JIN Tao-tao, CHEN Xiao-fan, Smedley K M. A new one-cycle controlled FACTS element with the function of STATCOM and active power filter[C].//Industrial Electronics Society, 2003. IECON' 03. The 29th Annual Conference of the IEEE. 2003: 2634-2638.

[6] Ucar M, Ozdemir E, Kale M. An analysis of three-phase four-wire active power filter for harmonic elimination reactive power compensation and load balancing under non-ideal mains voltage[C]. // Proc of the 35th Annual IEEE Power Electronics Specialists Conference PESC. 2004:3089-3094.

[7] SHI Guo-ping, QIAN Ye-wang, XU Wei-bing, HAN Chun-bao," Study of Three-phase Four-leg STATCOM Based on Dual-DSP Control ", $6^{\text {th }}$, vol. 45, Power Electronics, 2011, pp.35-37

[8] WU Lei, ZHAO Xiao-lin, XIA Nan, CAO Pei,"The Research of Shunt Three-phase Four-wire APF Current Detection", 6 ${ }^{\text {th }}$, vol. 45, Power Electronics, 2011, pp.47-49

[9] Zhang Mingguang, Hou Zhijun, "Research of Shunt Active Power filters in Three-phase Four-wire System With Non-linear Loads". $2^{\text {nd }}$, vol. 32, Electric Automation, 2010, pp.63-65 